\title{
Telework Triggered by Epidemic: Effective Communication Improvement of Telecommuting in Workgroups during COVID-19
}

\author{
Jiaze Ma \\ Moorpark College, Moorprk, CA, USA \\ Email: tonyma831@gmail.com
}

How to cite this paper: Ma, J. Z. (2021). Telework Triggered by Epidemic: Effective Communication Improvement of Telecommuting in Workgroups during COVID-19. American Journal of Industrial and Business Management, 11, 202-214.

https://doi.org/10.4236/ajibm.2021.112013

Received: January 6, 2021

Accepted: February 21, 2021

Published: February 24, 2021

Copyright $\odot 2021$ by author(s) and Scientific Research Publishing Inc. This work is licensed under the Creative Commons Attribution International License (CC BY 4.0).

http://creativecommons.org/licenses/by/4.0/

\begin{abstract}
The COVID-19 pandemic has unleashed a public health crisis globally and has compelled many people to work from home. Telework thus enables them to carry out their work remotely and to keep the company running smoothly. This study aims to provide insights for organizations in terms of telecommuting on effective communication, using combined desk research with synthesized data from various sources. The research identifies the benefits and drawbacks of telework in the first place. The author then discusses whether telecommuting will persist in the future. In the end, managers and employees are encouraged to enhance communication from several perspectives since telework will probably be realized in the near future. At the same time, companies and organizations should take quick actions as a response to the changing pattern of work.
\end{abstract}

\section{Keywords}

Telework, COVID-19, Companies

\section{Introduction}

The influence of telecommuting on communication efficiency lies in that it makes communication more efficient and faster. Video and telephone communication can improve team collaboration efficiency, and virtual reality teleconference and a cooperative office in the $5 \mathrm{G}$ era will be in fashion. Before COVID-19, telecommuting can be used as a tool for the flexible management of human resources and the promotion of marketing mode transformation, so as to 
improve the communication efficiency among team members, teams, and organizations, so as to enhance the potential level of sustainable development of enterprises.

According to Global Workplace Analytics, there were 1.8 million telecommuters in China in 2005, 3.6 million in 2014, and just under 5 million in 2018. In the US, 30 million people Work from Home (WFH), or 16 to 19 percent of the working population. The more international the organization, the more receptive and adaptable it is to telecommute. In particular, Google, Facebook, Twitter, and other Internet giants even set working from home as an employee benefit (Global Workplace Analytics, 2020). However, due to COVID-19, a great number of workforces begin to work at home which is so-called telework. According to statistics, nearly $60 \%$ of the US current workforce (Gajendran \& Harrison, 2007 ) and nearly 50\% EU workforce are working remotely (Globalworkplaceanalytics, 2020).

\section{Literature Review}

Telecommuting, known as telework or remote work, is a technology-driven mode of work. It is the most well-known form of distributed work and has become a widespread practice. Telecommuting (also known as working from home) is a work arrangement in which employees work outside the office, usually at home or close to home (including cafes, libraries, and various other locations) (Gajendran \& Harrison, 2007). Rather than traveling to the office, employees "travel" via telecommunication links and stay in touch with co-workers and employers via phone and email. Workers may occasionally enter the office to attend meetings and contact their employer. Work remotely from the delivery site use information and communication technologies (ICT) (Beattie \& Ellis, 2017). This simply refers to individuals working at households rather than offices due to various reasons.

Telecommuting practices include multiple aspects (Gajendran \& Harrison, 2007):

1) use of a variety of work locations (i.e., a central office, a home, or in a third location, such as a satellite office);

2) importance and types of ICT use;

3) the contractual relationship between the organization and remote workers (i.e. employees, self-employed workers, or contractors);

4) location time distribution (i.e. the proportion of working hours outside the central office).

\section{Effective Communication}

Communication refers to the process that people were informed and guided to reach a positive result. In other words, effective communication involves not only the ways managers talk guide their employees but also the methods the managers catch adequate attention from staff (Beattie \& Ellis, 2017). 
Communication is complicated in terms of organizational management. Apart from the human resource department in every organization, there should be a specific communication process which is isolated in the organization, and managers should well manage communication process within the companies in order to deal with conflicts or motivate employees (Bucăța \& Rizescu, 2017). In general, a successful communication process can enhance job satisfaction, efficiency, and productivity. Moreover, Bucăța \& Rizescu also listed two models which are: organization relationship between types of managerial problems and managerial decisions in communicating perspective, and organizational culture and communication (Bucăța \& Rizescu, 2017). These two models emphasized the significance of effective communication and managerial decision with the organizations. In short, internal effective communication involves not only stimulation or encouragement of employees but also sufficient professional information to reach certain fulfillment of both employees and the company itself.

Therefore, the process of communication in a business is therefore an integral mechanism, a basic administrative method. The role of the contact is to be used as a management mechanism to facilitate ties between citizens and to establish an atmosphere that is favorable to the internal growth of the organization.

Though telework has many conveniences for employees, whether to decide telework to become a part of the future of an organization is still controversial and it is not seen as a positive working style since there are some unstable factors that determine further productivity or profits of the company (Harker Martin \& MacDonnell, 2012). Managers are unwilling to implement telework programmers. As far as findings are concerned, there is no conclusive proof that teleworking enhance worker satisfaction and efficiency, so three avenues for future studies are suggested: consider the community and organizational level to clarify the effect of teleworking on various jobs, rethink the motives for teleworking (Bailey \& Kurland, 2002). Telework is especially important to improve the successful fulfillment of teams and individual remote-jobs, while at the same time providing a method to reduce the social alienation of remote workers (Venkatesh \& Speier, 2000).

Just as Mello (2007) stated, Teleworking, however, affects the dynamics of the employer-employee relationship which, if not applied strategically, can have a variety of negative consequences on the company. Six key issues on the organization of telework on the meaning (Ellison, 1999), calculation and reach of telework; the management of teleworkers; the effect of telework on travel; the corporate atmosphere and alienation of employees; the boundary between home and work; and the impact of telework on individuals and families.

\section{Research Question}

Based on a short review and discussion in the previous section, the main research question is raised as follows:

What are the improvements for telecommuting on communication manage- 
ment to optimize?

Two more sub-questions are needed to address the main issue.

1) What are the advantages and disadvantages of telecommuting?

2) What are the factors related to telecommuting that influence communication for organizations regarding global pandemic?

3) What is the future tendency of telecommuting in the world?

\section{Methodology}

\section{Literature Research Method}

The literature research method is applied to obtain information by investigating related literature including research, articles, or sources from official websites, etc. It aims to comprehensively and correctly understand and master the problem to be studied. Literature research is widely used in various disciplines. This research sourced data from official websites and results concluded from academic articles to reach findings. Firstly, the researcher sourced from academic articles to discuss the benefits and shortcomings of telework. Secondly, the researcher sourced from articles and another official website such as Statista or government websites to analyze factors influence effective commutations. Finally, data from official websites and from previous research were combined in order to find whether telework will be the future trend. The author then synthesized and contrasted findings in order or contribute to a new field of knowledge and fill a knowledge gap in terms of relations between future telework and effective communication process within organizations.

\section{Findings}

\subsection{Benefits of Telecommuting}

1) It improves the communication efficiency of enterprise teams through telecommuting under COVID-19

Telecommuting, online clocking, video conferencing, and video recruitment interviews provide technical support for the interpersonal, team, and organizational communication. Non-local offices such as home offices, remote offices, and mobile offices can make the operation cost of enterprises lower.

However, problems such as labor shortage, internal stability of the organization, and employee panic still exist within the company. How can an enterprise cope with global public events in an active and effective way? Telecommuting, as a tool, can strengthen flexible management of human resources, promote the transformation of the marketing model, etc., so as to improve the communication efficiency between teams and organizations, so as to enhance the potential level of sustainable development of the enterprise (Zhang, 2020b).

2) Flexible human resource management \& Innovated traditional performance appraisal mode and realize result-oriented performance appraisal

Information can be transmitted timely across countries, regions, industries, and enterprises due to technological progress, but information asymmetry still 
exists. It is especially important for people, enterprises, organizations, and groups to trust each other (Wen, 2020).

3) Construct flexible work system to realize the innovation of organizational system with flexible work mode

A flexible working system means that working hours, working places, working methods, and employment methods (in addition to the signing of labor contracts, third-party cooperation, outsourcing, temporary employment, etc.) can be deployed according to needs. The flexible working system and flexible working mode enable enterprises to quickly adjust enterprise size, strategic objectives, and production and operation mode (Liu, 2020).

According to the actual situation of employees and organizational task assignment, the business managers can adjust and classify the management. Such as reasonable deployment of outsourcing services, core technology, peripheral RESEARCH and development, collaborative work, telecommuting, and other different communication and processing methods, the deployment of human resources can reshape the organizational business system, and then innovate the organizational system (Abulibdeh, 2020).

\section{4) Improve staff skills and optimize training system}

After the outbreak of the epidemic, it was difficult for employees to return to work, talents in key positions were not available, and the resumption of work and production was blocked. In particular, asset-light and high-tech enterprises with outsourcing research and development and service were particularly prominent. At the information communication level, online communication, "cloud service" and instant telephone and video conference can alleviate the "think tank" problem (Harker Martin \& MacDonnell, 2012).

5) Transformation from traditional marketing to CUSTOMER relationship management

Online office and enterprise information management is the trend of The Times, the traditional enterprise should not only maintain current customer resources, but also develop new markets, using the outbreak can reshape the enterprise industry chain, transferring the core of the marketing business to the customer relationship management, use of B2C thinking, such as using CRM as the first universal office means (Zhang, 2020a), one is to reduce customer relationship maintenance costs, the second is to dig valuable customers continue to follow up, 3 it is rapidly to form new interactive management, realize the transformation of customer relationship management service, for customers tailored one-click solution, very beneficial to the promotion of the competitiveness of the enterprise.

\subsection{Drawbacks of Telecommuting}

However, there are still some drawbacks of telecommuting. Some employees cannot telecommute because their organization does not allow it (Koh, 2013). On the other hand, even if the organization offers options, some employees 
cannot commute as their supervisors do not approve the arrangement (namely that, supervisors often act as gatekeepers) (Koh, 2013).

Another case is that, within other organizations that support telecommuting, some employees may be hampered by the nature of their work, such as front-line customer service. Moreover, some employees may not be able to get the technical support they need to commute. Organizations dealing with confidential information often use virtual protocol networks (VPNs) for external access, thus, employees commuting to work need a company-approved VPN account for laptop computers and home Internet access. Furthermore, some employees can commute according to their needs but can choose not to commute (Koh, 2013).

Changing the workplace from a regular office to a home or other location is likely to change the frequency, quality, and, by definition, the way people interact with other organization members. Telecommuting gives employees the option of working away from a central location. By saving transport trouble, time, and staff money, it can also reduce work costs and (in many cases) eliminate the need for formal business attire. By offering telecommuting opportunities, such an arrangement can also symbolize an employer's willingness to change the work environment according to the needs of the employee (Gajendran \& Harrison, 2007). If commuting is meant to enhance people's autonomy and reduce work-family conflict, this, in turn, will enhance work-related attitudes, improve performance and reduce stress. At the same time, if telecommuting also destroys important work relationships and impedes career advancement, it means that work and non-work areas of achievement come at the expense or are negatively correlated with work in a relationship or social areas (Gajendran \& Harrison, 2007).

Managerial communication must consider several criteria (Burnside-Lawry, 2011). The first one is the specific structure of the information which can be understood easily and completely. Secondly, ensuring a fast information transmission. Thirdly, fluency and guarantee of correspondence reversibility. Fourthly, the communication channels should be simplified as much as possible. Lastly, ensure the stability and adaptability of the communication network to be used for any circumstance.

\subsection{Factors Related to Telecommuting That Influence Communication for Organizations Regarding Global Pandemic}

Telecommuting is seen as quite easy for employees to adapt (Travares, Santos, Diogo, \& Ratten, 2020). Similarly, the majority of respondents considered remote work to be a positive and rewarding experience (Varrella, 2020). At the same time, most of the respondents did not feel working from home to be too heavy or complicated. Moreover, only one-third of them felt that smart work was alienating and exhausting.

There are some shortcomings of this specific way of working (Travares, Santos, Diogo, \& Ratten, 2020). One thing is that there is a lack of cohesion among 
coworkers. In other words, some workers need professional interactions or communication where telecommuting may not realize. Similarly, employees have struggled because they also did not have enough infrastructures such as printers or other equipment of office, which is seen as inconvenient. Similarly, with numerical data shown from Statista (Varrella, 2020), the majority of the interviewers are willing to work from home. Four countries' employees were analyzed seen in Figure 1 which are the US, Germany, United Kingdom, and China. From this, it can be concluded that nearly $90 \%$ of employees are willing to work at home but only a few of employees see telework without challenges. In other words, roughly $65 \%$ of employees find difficulties of remote work in terms of lacking resources, corporations with coworkers, space at home. Another issue raised is that employees may come across problems in terms of arranging schedules and balance between family and work, e.g., accompanying children or marriage. This could suggest that even though telework is becoming necessary or popular, people still coming across different types of challenges when doing that.

A research has concluded that, factors that impact effective telework are ranged from gender, age, educational level, working experiences and experiences of telework (Raišienè, Rapuano, Varkulevičiūte, \& Stachová, 2020). After analyzing all the results of the report, the best candidate for the remote will be someone who has the following characteristics: being a millennial woman with a higher education degree, 4 - 10 years of professional experience, and working from home two days a week in a managerial and administrative position. Around the same time, the least happy remote worker seems to be a baby boomer male with a college degree, $20+$ years of career experience, and who has just begun working remotely.

The explanation for this is that telework is more rewarding for youthful, middle-aged professionals who can mix telework with office work and have ample technical and telework expertise (started teleworking before quarantine).

In the meantime, older workers who worked nearly three or more days a week
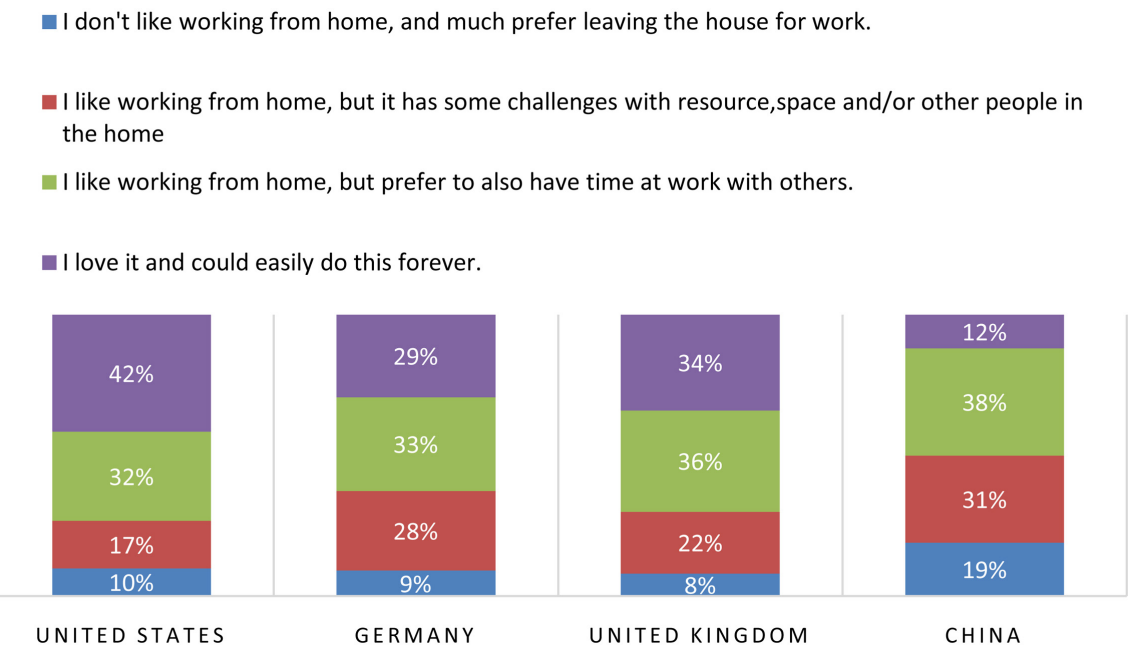

Figure 1. Perspectives of telework sourced from four countries. 
before quarantine were less pleased with teleworking, particularly those who moved their entire job to a virtual contact and coordination atmosphere during quarantine.

At the same time, some benefits and drawbacks were established. Teleworking, for example, may minimize unwanted gossip among workers. Conversely, during quarantine, those who served remotely stressed the need for socialization rather than quarantine.

\subsection{Future Tendency of Telecommuting in the World}

The rise of the "online economy" offers opportunities. Corporate office software has leapt to the top of the APP Store, distance learning has boosted sales of the iPad, and full online car purchases are also on the rise. In the face of the epidemic, online food shopping, online education and online office came to the front, and even heavy assets such as real estate, promoted by the Internet platform, set off a wave of online house viewing and online contract signing, which accelerated the process of real estate digitization (Zhang, 2020b).

Remote work has proven to be a successful alternative for several businesses and staff over the year. Although some businesses are anxious to bring their workers back to the workplace, others are already making moves that could permanently shift vast numbers of employees to remote jobs in the near future. New research reveals how a large number of the company's divisions are expecting to continue operating remotely five years from now.

According to a recent study published by Upwork, almost 23 percent of U.S. work teams and divisions are preparing to begin operating remotely five years from now. This is an improvement of more than 10 percentage points relative to the amount operating remotely before the pandemic. About 63 percent of teams and agencies are preparing to return to a completely remote workflow, while about 15 percent claim they will operate partly remotely in the next five years - a rise of almost six percentage points from the pre-pandemic era. Overall, research in some organizations reveals that remote work has grown to become an equivalent-if not stronger-alternative to in-office work in 2020. Several months of fine-tuning hierarchical processes within a remote environment have contributed to a new normalization of activities and projects. According to Upwork, self-employed employment is also a burgeoning development as more people feel attracted to a more stable, remote lifestyle of work. Since many businesses are now more used to the resources and technology required to operate remotely, freelancers have become a more enticing choice for many employers (Varrella, 2020).

According to the research (Ozimek, 2020), which results reflect the views and plans of those who have a direct impact on corporate telework decisions. The research suggests that the telework experiment is going better than expected for hiring managers. The perceived benefits of teleworking have led companies to significantly increase their plans for remote hiring in the future, which will acce- 
lerate the already upward trend of more remote work. Similar to the research have concluded that the interaction between everyday COVID-19 job setbacks and fatigue would be more favorable for teleworkers with higher work-to-worker interdependence (Chong, Huang, \& Chang, 2020), but companies could ease the positive relationship between end-to-day exhaustion and next-day work-out actions by offering higher telework-to-work help to employees.

\subsubsection{Technical Interaction Makes Communication More Efficient and Convenient}

With the continuous expansion of the company's business areas, regions, and customer resources, more and more personnel interact and communicate through E-mail, short messages, and instant messaging tools, which can not only reduce the cost of space and time communication but also make communication more efficient and faster (Ding \& Molina, 2020).

\subsubsection{Video Communication Will Realize "Face-to-Face" Communication}

Face-to-face requests are more than twice as successful as those made via email. Video calls can see the body language and micro-expressions of the other person in the context of the conversation, providing valuable visual clues for all parties and generating empathy in the context of the conversation. Leaders in the future could use videoconferencing regularly and schedule "social time" during meetings. Through "social time", employees can keep up with each other and enjoy each other's company, thus increasing the sense of closeness between teams and improving the efficiency of teamwork (Ding \& Molina, 2020).

\subsubsection{Telephone Communication to Feel Emotional Changes}

Written words cannot make the other party feel the changes of expression, emotion, and body language. The tone of voice communication can endure different dimensions and levels of language and express different emotions. At the same time, it can share and communicate feelings with others to achieve effective communication.

\subsubsection{Virtual Reality Teleconference and Collaborative Office Will Be the Trend in the 5 G Era}

The virtual reality environment can break through the time and space constraints and has the temporality, can feel and truly restore the real meeting scene and communication mode, stereo images and audio can enjoy the immersive experience. The $3 \mathrm{D}$ conference, relying on virtual reality technology, is applied in remote meeting collaboration, such as team meetings, training, launch event, exhibition, distance education, and so on. The conference scale of the 3D conference can reach tens of thousands of people.

\section{Discussion \& Results}

Telecommuting or telework is becoming a trend especially under the global pandemic background, where individuals from different industries are forced to work at home. The desk research has managed to answer three sub-questions as 
thoroughly as possible. The benefits of telecommuting are various:

1) Improve the communication efficiency of enterprise teams;

2) Reach flexible human resource management under the epidemic situation;

3) Innovate traditional performance appraisal mode and realize result-oriented performance appraisal;

4) Construct a flexible work system to realize the innovation;

5) Enhanced collaborative creation of organizations and implement flexible salary system;

6) Improve staff skills and optimize training system;

7) Transformation from traditional marketing to CUSTOMER relationship management;

8) Cost-efficient.

However, the research also reveals some drawbacks of telework. For instance, there is no sufficient equipment or infrastructure for telework when employees at home. They may ask for printers or more professional support in terms of skills or other necessary things. Moreover, employees find it hard to manage and balance work and home from telework, e.g., children, family time, or working schedule. This could suggest that telecommuting is harming the internal communication environment to some extent under outbreak.

Another result is that telework is influenced by many precited factors such as age, gender, educational level, working experiences, telework experiences of employees. For instance, females may find it interesting and easy to handle work at home whereas males are more interested in working at an office. Similar to drawbacks, lack of resources and space or corporations within teamwork are also affected characteristics of commuting.

The future of telework in $5-10$ years is expected to be realized. The user habits of telecommuting will further increase globally in the future, but previous solutions have technical, equipment, software, or infrastructure shortcomings that cannot match the needs of enterprises and employees, especially in some of the more specialized application scenarios, such as complex 3D rendering, high-precision physical simulation, low-latency VR\&AR, etc. Virtualized office is the best solution, virtualization can provide an excellent user experience for remote employees while ensuring the security of sensitive data.

In summary, the benefits of telework outweigh its drawbacks. Although there are risk factors of telework, telework will be a trend in the future.

\section{Conclusion}

In order to benefit from this trend, policymakers must aim to accelerate creativity and efficiency growth by encouraging the universal use of telework. Managers must be mindful that perseverance in learning how to communicate should be a high priority for them as a core talent which they must procure or refine in order to achieve the anticipated outcomes set out in the goals of the business. The way of performance appraisal changes with it and gradually changes into 
more quantifiable appraisal indicators. On the one hand, enterprises should be flexible in dealing with formal punching and attendance; on the other hand, achieve results-oriented performance appraisal.

Another recommendation is that, to pay attention to the collaborative creation of organizations and implement a flexible salary system. Cross-departmental collaboration is the key to improve organizational efficiency within an enterprise. From the perspective of collaboration, for telecommuting employees, due to regional and temporal differences in work, the human resource management department not only needs to carry out online collaboration but also needs to complete online and offline communication and coordination. From the perspective of the definition of authority and responsibility of departments in a special period, it is necessary to create a "community of interests" for all members-all members should have the collective consciousness of sharing interests and risks, so as to avoid the buck-passing caused by factors such as multiple departments and management levels. From the perspective of distribution mechanism, the flexible salary system of individual employee salary performance and team organization goal decentralization and comprehensive evaluation should be implemented, so that the work quality and organizational performance of employees can be full of vitality during the epidemic period.

In terms of recruitment methods and employment system, it is necessary to excavate external talents to make up for the shortage of internal human resources. At the level of constructing and reshaping the training system, enterprises are required to pay full attention to the growth of employees, to enable employees and extensively develop their skills, so as to meet the immediate needs of enterprises for human resources through the mutual supplementing of employees within enterprises (Liu, 2020).

Subsequently, according to the results of the research, more specifically, managers shall take into account factors that may influence the telework of employees. Females may be more advised to work at home compared to males, and managers should encourage telework for employees with higher education and over 20 years of working experience. Moreover, it is recommended to train employees in terms of time management and provide physiology support for long-term telework employees. Meanwhile, companies shall make sure to provide adequate equipment or infrastructure for telework to ensure effective and enough communication or corporation among the staff.

Lastly, both managers and organizations shall prepare to accept the future trend of telework so as to adopt new technology and working environment. This suggested that they should provide enough training in terms of IT skills, remote language skills, remote corporations, communication skills remotely, etc. (Carol Rozwell, 2020).

\section{Limitations and Future Research}

This study is a directional study based on COVID-19. Although there are certain 
people who have studied what teleworking is, because COVID-19 is a recent global event, we cannot accurately derive solutions to accurately deal with intra-company communication through very few statistics or literature studies. Future relevant research could be about three areas.

\section{Conflicts of Interest}

The author declares no conflicts of interest regarding the publication of this paper.

\section{Availability of Data}

Ensure that people who work from home as a result of COVID-19, or who already work from home and continue to do so, can be interviewed. This will ensure the integrity of the sample as well as the accuracy of the data.

\section{Bias Due to Cultural or Personal Factors}

Researchers may be biased by their cultural background and personal claims about a particular phenomenon, and this bias may affect the validity of the study. Also, the researcher may only cite information or results that support their own research hypothesis. To avoid this problem, one should interview people from different countries and try to enlarge the sample as much as possible. This will allow directional recommendations and decisions to be made for companies in different countries.

\section{References}

Abulibdeh, A. (2020). Can COVID-19 Mitigation Measures Promote Telework Practices? Journal of Labor and Society, 23, 551-576. https://doi.org/10.1111/wusa.12498

Bailey, D. E., \& Kurland, N. B. (2002). A Review of Telework Research: Findings, New Directions, and Lessons for the Study of Modern Work. Journal of Organizational Behavior, 23, 383-400. https://doi.org/10.1002/job.144

Beattie, G., \& Ellis, A. W. (2017). The Psychology of Language and Communication. London: Routledge. https://doi.org/10.4324/9781315187198

Bucăța, G., \& Rizescu, A. M. (2017). The Role of Communication in Enhancing Work Effectiveness of an Organization. Land Forces Academy Review, 22, 49-57. https://doi.org/10.1515/raft-2017-0008

Burnside-Lawry, J. (2011). The Dark Side of Stakeholder Communication: Stakeholder Perceptions of Ineffective Organisational Listening. Australian Journal of Communication, 38, 147.

Carol Rozwell, M. (2020). How to Shape an Efficient Telecommuting Mode. Intelligent Manufacturing, No. 3, 20-22.

Chong, S., Huang, Y., \& Chang, C. H. D. (2020). Supporting Interdependent Telework Employees: A Moderated-Mediation Model Linking Daily COVID-19 Task Setbacks to Next-Day Work Withdrawal. Journal of Applied Psychology, 105, 1408-1422. https://doi.org/10.1037/apl0000843

Ding, L., \& Molina, J. S. (2020). “Forced Automation” by COVID-19? Early Trends from Current Population Survey Data (No. 88713). Federal Reserve Bank of Philadelphia. 
Ellison, N. B. (1999). Social Impacts: New Perspectives on Telework. Social Science Computer Review, 17, 338-356. https://doi.org/10.1177/089443939901700308

Gajendran, R. S., \& Harrison, D. A. (2007). The Good, the Bad, and the Unknown about Telecommuting: Meta-Analysis of Psychological Mediators and Individual Consequences. Journal of Applied Psychology, 92, 1524-1541.

https://doi.org/10.1037/0021-9010.92.6.1524

Global Workplace Analytics (2020). Latest Work-at-Home/Telecommuting/Mobile Work/Remote Work Statistics. https://globalworkplaceanalytics.com/telecommuting-statistics

Globalworkplaceanalytics (2020). Work-at-Home after Covid-19-Our Forecast. https://globalworkplaceanalytics.com/work-at-home-after-covid-19-our-forecast

Harker Martin, B., \& MacDonnell, R. (2012). Is Telework Effective for Organizations?: A Meta-Analysis of Empirical Research on Perceptions of Telework and Organizational Outcomes. Management Research Review, 35, 602-616. https://doi.org/10.1108/01409171211238820

Koh, A. (2013). Dissecting Reasons for Not Telecommuting: Are Nonusers a Homogenous Group? The Psychologist Manager Journal, 16, 243-260. https://doi.org/10.1037/mgr0000008

Liu, B. (2020). Building Flexible Human Resource Management to Cope with Uncertain Environment. Humanities World, No. 161, 16-17.

Mello, J. A. (2007). Managing Telework Programs Effectively. Employee Responsibilities and Rights Journal, 19, 247-261. https://doi.org/10.1007/s10672-007-9051-1

Ozimek, A. (2020). The Future of Remote Work. Available at SSRN 3638597. https://doi.org/10.2139/ssrn.3638597

Raišienė, A. G., Rapuano, V., Varkulevičiūtè, K., \& Stachová, K. (2020). Working from Home-Who Is Happy? A Survey of Lithuania's Employees during the COVID-19 Quarantine Period. Sustainability, 12, 5332. https://doi.org/10.3390/su12135332

Travares, F., Santos, E., Diogo, A., \& Ratten, V. (2020). Teleworking in Portuguese Communities during the COVID-19 Pandemic. Journal of Enterprising Communities: People and Places in the Global Economy, ahead-of-print. https://doi.org/10.1108/JEC-06-2020-0113

Varrella, S. (2020). How Would You Consider Your Remote Working Experience? https://www.statista.com/statistics/1131618/attitudes-towards-remote-working-in-italy/

Venkatesh, V., \& Speier, C. (2000). Creating an Effective Training Environment for Enhancing Telework. International Journal of Human-Computer Studies, 52, 991-1005. https://doi.org/10.1006/ijhc.1999.0367

Wen, X. (2020). Research in Administration and Work Performance in Involuntary Remote Work in the Outbreak of Disease by Using Science and Technology. Master's Thesis, Hefei: University of Science and Technology of China.

Zhang, Y. (2020a). Thinking on Telecommuting Based on Epidemic Scenarios-Analysis Based on Financial Year-End Final Accounts. Chinese Management Informatization, 23, 78-80.

Zhang, Z. (2020b). On the Transformation of Marketing Work Mode of Traditional Enterprises in the Context of COVID-19 Epidemic. Liaoning Economy, No. 3, 94-96. 